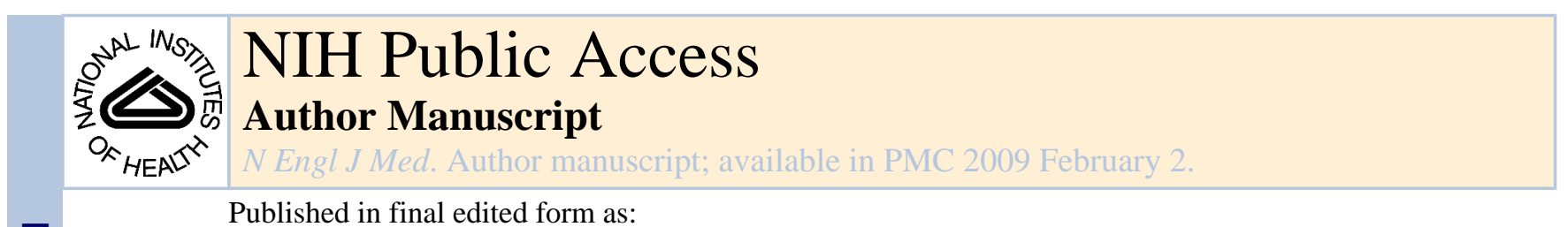

Published in final edited form as:

N Engl J Med. 2004 September 16; 351(12): 1264-1265. doi:10.1056/NEJM200409163511224.

\title{
Was Rembrandt Stereoblind?
}

\author{
Margaret S. Livingstone and Bevil R. Conway \\ Department of Neurobiology, Harvard Medical School, 220 Longwood Ave., Boston, MA 02115
}

\begin{abstract}
Stereopsis is an important cue for depth perception, yet it can be an hinderance to an artist trying to depict a 3-D scene on a flat surface - art teachers often instruct students to close one eye in order to flatten what they see. Therefore stereoblindness might not be a handicap, and might even be an asset, for some artists. Stereopsis requires precise alignment of the two eyes. On examining a number of self portraits of Rembrandt, a great artist recognized for his astute observation, we noticed that many of them show his eyes as exotropic, to an extent that would be incompatible with normal stereopsis. We asked whether the gaze angle of the eyes in his self portraits was simply random, or whether the gaze deviation was systematic, as it would be if he were accurately portraying a feature of his physiognomy.
\end{abstract}

We examined high resolution images of the oil paintings and etchings listed in a comprehensive catalogue of Rembrandt's self portraits spanning his career (1). Most show one eye gazing directly at the viewer and the other eye deviating laterally (figure 1). We quantified this pattern in all the Rembrandt self portraits in which both eyes could be seen well enough to estimate the position of the pupil (or the center of the iris) within the opening between the eyelids (24 oil paintings, 12 etchings). For each portrait, measurements were made by aligning an ellipse with the eye contour, then aligning a circle with the circumference of the iris, and measuring its horizontal position along the eye contour. We noted: First, Rembrandt portrays his eyes as exotropic in 35 out of 36 self portraits. Second, in 23 out of 24 paintings, the eye on the right side of the painting tends to look straight ahead while the other eye deviates outward, whereas in 12 out of 12 etchings this asymmetry is reversed (figure 1).

Because an etching is made by scratching lines on a metal plate that is used to print an image, what you see in the print is left-right reversed from what the artist drew on the plate. The fact that in general the outward deviating eye in the etchings is opposite from the outward deviating eye in the paintings suggests that Rembrandt actually did have a unilateral strabismus-otherwise the deviating eye should be random.

\section{Acknowledgments}

Supported by the National Eye Institute and the Harvard University Society of Fellows.

\section{Reference}

1. White, C.; Buvelot, C., editors. Rembrandt by Himself. London: National Gallery Publications; 1999. The self portraits examined were catalogue numbers: $3,11,18,20,26,27,33,35,36,37,38,39,40$, $41,42,44,49,51,53,54,57,59,60,62,64,65,68,69,71,73,74,79,80,81,84,86$.

Please address all correspondence concerning this manuscript to: Margaret S. Livingstone, Telephone: 617432 1664, Fax: 6174320210 , Email: mlivingstone@hms.harvard.edu. 


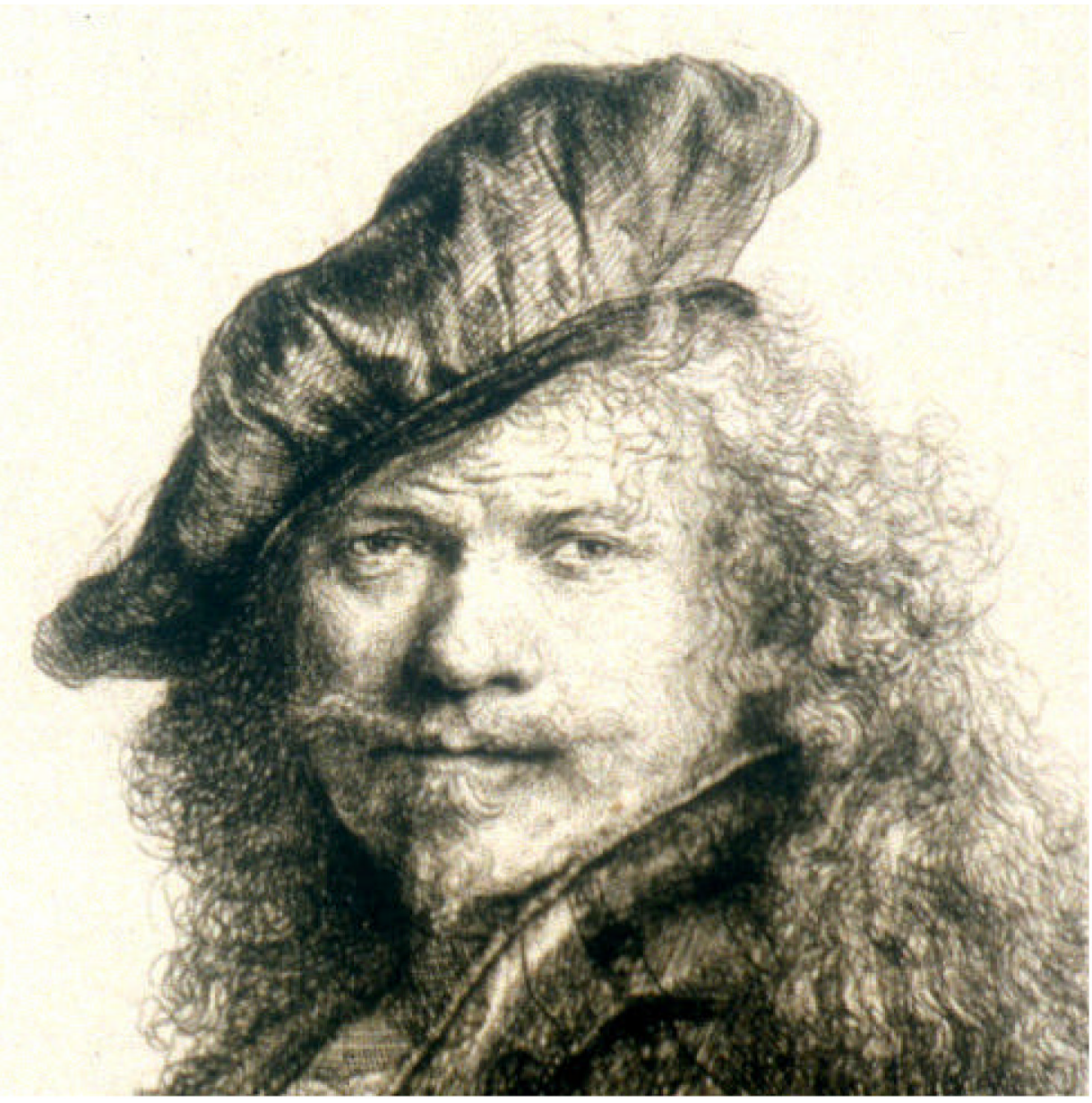

Figure 1.

Self Portrait leaning on a stone wall (detail). 1639. London, British Museum, inv. no. 1868-8-22-656. 